\title{
Conflictos en la Audiencia de Quito a finales del siglo XVIII ${ }^{1}$
}

\author{
Miguel Molina Martínez \\ Universidad de Granada
}

El presente trabajo se ocupa de estudiar los conflictos surgidos en la Audiencia de Quito durante las presidencias de José García de León y Pizarro y Juan José de Villalengua. Estos conflictos surgieron después de las denuncias y quejas interpuestas por diferentes individuos, todos descontentos con la política realizada por aquéllos. Se les acusó de abuso de poder, cohechos y prácticas fraudulentas. El presidente-regente García Pizarro fue el blanco principal de las críticas, mientras que su yerno y sucesor Villalengua trabajó para frenar los ataques. Dentro de la Audiencia, el oidor Fernando Cuadrado encabezó el movimiento opositor. La Corona no pudo evitar que este tribunal atravesara una grave crisis, que recordaba sucesos similares en la primera mitad del siglo XVIII. Este artículo analiza algunas claves del conflicto y revela los intereses particulares que animaban a cada uno de los bandos en litigio.

Palabras ClaVE: Audiencia de Quito, siglo XVIII, 1778-1789, conflicto institucional, grupos de poder.

This essay studies the conflicts arisen in the Quito Audience during presidencies of José García de León y Pizarro and Juan José de Villalengua. These conflicts arose after the accusations and complaints interposed by different individuals all dissatisfactions with the politics carried out by those. They were accused of abuse of power, bribes and practical fraudulent. The president-regent García Pizarro was the main target of the critics, while its son-in-law and successor Villalengua worked to brake the attacks. Inside the Audience the hearer Fernando Cuadrado headed the movement opponent. The Crown could not avoid that this tribunal crossed a serious crisis that she remembered similar events in the first half of the XVIII century. This article analyzes some keys of the conflict and he reveals the particular interests that encouraged each one of the decrees in litigation.

KeYworDs: Quito Audience, $18^{\text {th }}$ century, institutional conflict, power groups.

El estudio de la Audiencia de Quito durante las presidencias de José García de León y Pizarro (1778-1784) y Juan José de Villalengua y Marfil (1784-1789) constituye un buen ejemplo del espíritu de partido imperante

1 Este artículo forma parte del Proyecto I+D HUM 2005-03410/HIST del Ministerio de Educación y Ciencia, sobre "La dinámica de los grupos de poder en Quito, siglos XVII, XVIII y XIX". 
en su seno y un fiel exponente de los conflictos que enfrentaron a sus miembros. La imagen que ofreció aquel alto Tribunal no fue desde luego la más edificante y pone en entredicho la integridad, pureza y buen hacer que su propia normativa y ordenanzas establecían. Por aquel tiempo sus integrantes parece que estuvieron más atentos a resolver sus diferencias que al ejercicio de la administración de justicia y también más preocupados por sus intereses particulares que por el servicio público. No era la primera vez que las tensiones afloraban, puesto que ya en la primera mitad de la centuria - particularmente durante la presidencia de José de Araujo y Río- la situación llegó a ser bastante convulsa y la rivalidad entre facciones alcanzó graves extremos. ${ }^{2}$ En las líneas que siguen se expondrán algunas de las claves que desencadenaron los enfrentamientos en aquella Audiencia y que obligaron a la Corona a intervenir para detener su deterioro.

En 1788, a instancias del monarca Carlos III, una iniciativa del virrey de la Nueva Granada, Francisco de Gil y Lemos, encaminada a esclarecer ciertas denuncias y acusaciones vertidas contra José García de León y Pizarro durante el tiempo de su presidencia y contra su hermano Ramón, gobernador de Guayaquil desde 1779, puso en marcha la pesquisa que terminaría desvelando abusos, cohechos y rivalidades que salpicaron a todos los protagonistas. El proceso generó una ingente masa documental, cuyo valor radica en el hecho de aportar nuevos puntos de vista sobre el ejercicio del poder y las pautas de comportamiento de aquellos funcionarios reales. ${ }^{3}$ Bajo aparentes conductas de respeto a la legalidad, se atisban gestiones que rozaban lo ilegal o que eran moralmente indefendibles. Junto a ello, no faltan estrategias dirigidas a satisfacer egoísmos individuales y de grupo. En suma, esta documentación ofrece un panorama poco alentador acerca del normal funcionamiento de la institución judicial y, por otro lado, permite dibujar una realidad marcada por las pugnas y las tensiones que enfrentaron a sus ministros.

2 Sobre este momento véanse los siguientes trabajos de Ramos Gómez, Luis Javier: "La estructura social quiteña entre 1737 y 1745 según el proceso contra Don José de Araujo“, Revista de Indias, LI, 191, Madrid. 1991, págs. 25-56; "La pugna por el poder local en Quito entre 1737 y 1745 según el proceso contra el presidente de la Audiencia José de Araujo", Revista Complutense de Historia de América, 18, Madrid, 1992, págs. 179-196; "La acusación contra el presidente electo don Juan José de Araujo y Río por la introducción de mercancías ilícitas a su llegada a Quito en diciembre de 1736“, Boletín de la Academia Nacional de Historia, LXXII, 153/154, Quito, 1993, págs. 249-272.

3 La mayor parte de ella puede consultarse en el Archivo General de Indias de Sevilla (en adelante AGI), Quito, 267, 271 y 272. 
La Audiencia de Quito era a finales de los ochenta el escenario en el que se dirimieron asuntos que comenzaron a gestarse una década antes y, en gran medida, propiciados por el singular comportamiento de José García de León y Pizarro. Éste había accedido a ella investido de amplios poderes. A su condición de visitador general, unía la de presidente-regente de la Audiencia, cargo de reciente creación, la de superintendente de Real Hacienda y la de capitán general. En realidad ninguna parcela de poder escapaba a su control; tal era el perfil de funcionario que la Corona había diseñado para acometer un vasto programa reformista en el reino de Quito. A diferencia del militar que le había precedido, José Diguja, José García de León y Pizarro era un hombre letrado poseedor de una sólida formación, experimentado y de carácter fuerte. Presumía de tener generosos apoyos en la Corte, en especial del ministro José de Gálvez, y de otros personajes influyentes como el virrey de la Nueva Granada, Caballero y Góngora, o el marqués de Loreto, virrey del Río de la Plata. No debe sorprender, por tanto, que su posición privilegiada le condujera a practicar un despotismo del que no escaparon las instituciones, los cargos y las personas de su entorno.

Había nacido José García de León en octubre de 1738 en Motril (Granada), en el seno del matrimonio formado por el coronel José García de León y la motrileña Francisca Pizarro y Rivera. Más inclinado por las letras que por las armas, cursó los estudios de Derecho en la Universidad de Granada doctorándose en 1760. Más tarde siguió la carrera de varas, desempeñando diferentes cargos en Alhama (1760), Úbeda (1763) y Jerez de la Frontera (1767) antes de ser corregidor en Baena (1771). Intervino en la audiencia granadina y en 1775 fue promovido a la de Sevilla en calidad de fiscal. Apenas llevaba desempeñando este cargo un año cuando Carlos III le nombró regente y presidente de la Audiencia de Quito; en este destino permaneció hasta 1784, fecha en la que regresó a Madrid para ocupar una plaza de consejero de Indias. ${ }^{4} \mathrm{Su}$ afán por escalar posiciones en la carrera administrativa le llevó a solicitar una plaza en la Cámara de Indias, ${ }^{5}$

4 El Real Título de su nombramiento data del 14 de marzo de 1783, habiendo jurado el cargo el 14 de agosto de 1786. AGI, Indiferente General, 894. Puede consultarse una breve reseña de su trayectoria en Burkholder, Mark A., y Chandler, D.S.: Biographical Dictionary of Audiencia Ministres in the Americas, 1687-1821, Greenwood Press, Londres, 1982, pág. 133.

5 AGI, Quito, 233. Representación de José García de León y Pizarro al rey, Madrid, 2 de octubre de 1786. En dicho escrito hacía una amplia exposición de su hoja de servicios con especial incidencia en la labor desempeñada en Quito y por la que creía justificada su solicitud. Al mismo tiempo aprovechaba para pedir al monarca "generosas señales para su esposa e hijo José María". En los mismos términos le insistía al Conde de Floridablanca mediante una carta fechada en Madrid el 19 de junio de 1787. AGI, Indiferente General, 885. 
que finalmente obtuvo. ${ }^{6}$ Murió el 30 de marzo de 1798 y fue enterrado en la madrileña iglesia de los Santos Justo y Pastor.

$\mathrm{Su}$ labor en Quito ha sido destacada favorablemente por aquellos historiadores que se han ocupado de su estudio. González Suárez afirmó que García de León y Pizarro fue "unos de los gobernantes más activos y diligentes del tiempo de la Colonia". ${ }^{7}$ Reig Satorres lo consideró un funcionario muy cualificado, que con decisión y competencia

"realizará el primer empadronamiento general de la Presidencia; lleva al detalle la fiscalización de las Cajas Reales como nunca se había logrado; mejora y ordena con buen conocimiento la administración de justicia, reajusta divisiones territoriales internas... logra un repunte fiscal tan asombroso, en un territorio empobrecido, que el mismo Gálvez en nombre del Rey, no podrá menos de felicitarle". ${ }^{8}$

\section{Los mismos elogios le ha dispensado Martiré al afirmar que}

"a la variada competencia demostrada en el ejercicio del gobierno se agregaba su versación jurídica... Es un conocedor de la materia que trata, maneja con soltura la legislación vigente y ha recogido a su paso por los tribunales de la Península una preciosa experiencia que vuelca en el escenario americano... Sus disposiciones son precisas y firmes, se ve en ellas la mano enérgica del magistrado acostumbrado a poner orden en pleitos y expedientes y a manejar con buen método los papeles de los tribunales".

El hecho de que el Rey le otorgara la Cruz de la Orden de Carlos III y lo acogiera entre los miembros de su Consejo de Indias avala la idea de que fue un funcionario que cumplió satisfactoriamente los objetivos de su

6 Nombrado por Real Cédula del 6 de noviembre de 1791, tomó posesión el 23 de dicho mes y año. AGI, Indiferente General, 894.

7 González Suárez, Federico: Historia general de la República del Ecuador, Quito, 1901, t. V, pág. 309. Existe una reedición más moderna de esta misma obra, publicada en tres tomos por la Casa de la Cultura Ecuatoriana, Quito, 1969-1970.

8 Reig Satorres, José: "Visita General a la Presidencia y Audiencia de Quito, realizada por el licenciado José García de León y Pizarro (1778-1784)”, en XI Congreso Internacional de Historia del Derecho Indiano. Actas y estudios, t. III, Instituo de Investigaciones de Historia del Derecho, Buenos Aires, 1997, pág. 123. págs. 121-146. En efecto, el marqués de Sonora le hacía saber lo siguiente: "Se ha enterado el Rey, con mucha satisfacción, del celo, actividad y desempeño, con que Vueseñoría le ha servido en los varios empleos y comisiones que se dignó poner a su cargo, y del visible incremento que ha tenido el Real Erario por sus acertadas providencias; y me manda que en su Real Nombre manifieste a Vueseñoría su real gratitud, asegurando lo muy satisfecho que se halla Su Majestad de sus operaciones y aciertos”. AGI, Quito, 267. Carta de José de Gálvez a José García de León y Pizarro, Aranjuez, 17 de abril de 1781.

9 Martiré, Eduardo: "La visita de García de León y Pizarro a la Audiencia de Quito (Aporte documental)", en V Congreso Internacional del Instituto de Historia del Derecho Indiano. Actas, en Anuario Histórico Jurídico Ecuatoriano, VI, Quito, 1980, págs. 325-326. págs. 323-346. 
gobierno en Quito, particularmente los económicos y fiscales. Su visita general tuvo efectos indudables sobre el estado de la región y su gobierno no dejó indiferente a nadie. ¿Dónde están entonces las críticas? ¿Por qué despertó tanta animadversión? La naturaleza del problema habría que buscarla fundamentalmente en la forma en que gestionó los asuntos de gobierno y en sus actitudes prepotentes, que con frecuencia rozaban el límite de la legalidad o se percibían simplemente como inmorales. Por otro lado, la impopularidad de sus medidas le acarreó un coste social nada desdeñable y, en fin, la arbitrariedad de muchas de sus decisiones conformó un nutrido grupo de descontentos, dispuestos a vengarse en la primera ocasión que se presentara. La habilidad del presidente-regente para rodearse de amigos y deudores corrió paralela a su capacidad para ganarse enemigos y en este contexto resulta fácil entender las tensiones que fue generando, hasta el punto de que al término de su mandato nadie dudaba de la existencia de un partido que le apoyaba incondicionalmente y de otro que le censuraba sin paliativos. En el primero se incluían, además de sus familiares, todos aquellos que de una forma u otra se habían sentido beneficiados por sus disposiciones; en el otro, por el contrario, quienes se consideraban perjudicados o relegados por las mismas.

No fue García de León hombre que ocultara sus preferencias o que se recatara ante determinados actos que pudieran parecer impropios de su elevada condición. En este sentido, el nombramiento de su hermano Ramón como gobernador de Guayaquil resulta incomprensible sin tener en cuenta las influencias y maniobras que llevó a cabo cerca de las autoridades competentes. ${ }^{10}$ Lo mismo cabe decir de la sorprendente designación del fiscal

10 Su mano es visible en el informe que la Audiencia de Quito remitió al Rey en septiembre de 1783 acerca de los méritos y servicios del gobernador de Guayaquil. En él los firmantes alaban su política y lo consideran merecedor de una promoción. Véase Arribas, Filemón: "Nuevas noticias sobre D. Ramón García de León y Pizarro, gobernador de Guayaquil”, Revista de Indias, XXX, 119-122, Madrid, 1970, pág. 29. págs. 21-48. Una exposición más detenida de su labor de gobierno puede consultarse en Castillo, Abel Romeo: Los gobernadores de Guayaquil en el siglo XVIII (Notas para la historia de la ciudad durante los años de 1763 a 1803), Archivo Histórico del Guayas, Guayaquil, 1978, págs. 193-253. Ramón García de León y Pizarro había nacido en Orán y desde muy joven mostró su predilección por la carrera militar. En 1752 servía como cadete del regimiento de aquella plaza africana donde promocionó en poco tiempo hasta el grado de capitán. Destacó en varias acciones de guerra en Ceuta y Tetuán. En 1773, ya en América, formó parte del batallón de Milicias Disciplinadas de blancos de Cartagena como sargento mayor. Ascendido a teniente coronel de Infantería, ocupó el cargo de gobernador interino de Río Hacha en 1777 y poco después desempeñó el gobierno de la provincia de Mainas. En 1779 fue designado para el cargo de gobernador de Guayaquil y en él se mantuvo hasta 1790. Continuó su labor gubernativa al frente de la intendencia de Salta y desde 1797 en la de La Plata. En esta última le sorprendieron los sucesos de 1809 que le obligaron a renunciar al cargo. Murió en Chuquisaca en 1815. 
Juan José de Villalengua para sucederle al frente de la Audiencia. No se trata sólo de que considerara a éste como un incondicional y fiel servidor suyo en la fiscalía del tribunal quiteño, sino que una calculada alianza matrimonial le llevó a casarlo con su hija Josefa García Pizarro y Frías en 1784, poco antes de su regreso a España. Así Villalengua vino a convertirse en el mejor valedor de su suegro y, al mismo tiempo, en el personaje idóneo para conservar la herencia recibida. ${ }^{11}$ De todo ello resultó que entre 1778 y 1789 el clan de los García y León desempeñó los más altos cargos en Quito y Guayaquil. Los directos vínculos familiares existentes entre aquellas autoridades favorecieron el surgimiento de intereses comunes encaminados a la promoción y consolidación del grupo. En torno a ellos se tejió una notable red de influencias que inevitablemente no tardó en despertar la oposición de otro amplio sector de la sociedad.

Las noticias sobre el malestar que la conducta del gobernador García Pizarro había suscitado durante su presidencia en Quito llegaron al Consejo de Indias — del que por cierto ya formaba parte - a finales de 1787 mediante sendas representaciones..$^{12}$ La redactada por Joaquín Pareja era la más dura y grave, ya que las críticas no sólo le implicaban a él, sino también a su hermano Ramón y a su yerno, el presidente de la Audiencia Juan José Villalengua. El autor de la denuncia comenzaba señalando que la lastimosa situación por la que atravesaba la ciudad de Guayaquil se debía a la pésima gestión realizada por José García de León durante el tiempo de la visita general. Consideraba que los estancos de la pólvora, tabaco y naipes que estableció entonces tuvieron efectos muy negativos para la población, al tiempo que reportaron pingües beneficios al visitador gracias a las cuantiosas gratificaciones recibidas de quienes fueron nombrados para su administración. Por otro lado, acusaba al obispo de Quito, Blas Sobrino y Minayo, de haber concedido al hijo del presidente, en concepto de capellanías, una cantidad que oscilaba entre los 70.000 y 80.000 pesos y de haber consentido que, siendo aún menor de edad, disfrutase el beneficio de la

11 Juan José de Villalengua y Marfil nació en Vélez-Málaga en 1747. Estudió leyes en la Universidad de Alcalá de Henares y con apenas 26 años ya ejercía en la Audiencia de Quito como protector de indios y como fiscal del crimen en 1776. Más tarde fue designado para ocupar el mismo cargo en la Audiencia de Lima; sin embargo, no llegó a tomar posesión de él ya que en 1783 fue propuesto para suceder a José García de León y Pizarro, por entonces ya su suegro, al frente del tribunal quiteño y en él se mantuvo hasta 1790.

12 AGI, Quito, 271. Una fue escrita por Joaquín Pareja, alférez real de Guayaquil, con fecha 4 de diciembre de 1787. La autoría de la otra correspondía a Antonio Marcos, abogado de Guayaquil, el 19 de diciembre de 1787 y fue presentada al Conde de Floridablanca por Domingo Sánchez Barrero. 
sacristía mayor de Guayaquil para arrendarla después por 1.000 pesos anuales. Estas denuncias no eran sino la punta de un iceberg que alcanzaría enormes proporciones más tarde, durante el desarrollo del proceso que se inició en 1788. Entonces los testigos manifestaron su descontento contra el presidente en una cascada de denuncias que lo dejaban muy mal parado. Un amplio sector de la opinión coincidía en la idea de que no había puesto ni cargo que pudiera obtenerse sin gratificación o soborno y que la venalidad se había instalado en todos los niveles de la administración. Tampoco se dudaba de que el presidente obtenía abundantes beneficios para sí mismo y sus familiares mediante estrategias de dudosa legalidad; aún más, que su mujer acumuló una inmensa fortuna en metálico, joyas y otros objetos valiosos gracias a su intermediación en los asuntos de gobierno y al margen de cualquier conducta moral. ${ }^{13}$

Las críticas contra su hermano Ramón ponían de manifiesto un enriquecimiento ilegítimo a costa del gasto de las tropas y de los propios de la ciudad de Guayaquil; de manera especial, se denunciaba el control abusivo que el gobernador había implantado en el Cabildo y que no dudaba en tachar de despótico. Pareja expuso con total franqueza las difíciles relaciones en las que se encontraban inmersos la institución municipal y el gobernador por las injerencias de éste en aquélla. Como ejemplo señalaba que

"en las elecciones de alcaldes ordinarios ha pedido votos y hecho mil vejaciones, no excusándose de recibir quinientos o mil pesos de los que pretendían los empleos; y si algunos se han resistido a darle el voto, los ha perseguido. Y aún para atemorizar en días de elecciones ha hecho cercar las casas del Cabildo de 30 ó 40 soldados con bayoneta calada y bala en boca". ${ }^{14}$

Proseguía la representación denunciando los fraudes que cometía en el comercio del cacao, la madera y la cal, arropado siempre por sus cómplices, el teniente de gobernador, José Mejía, y el comandante de milicias, Miguel de Guevara. El testimonio de Pareja llegó a Madrid avalado por las firmas de la mayoría del Cabildo. ${ }^{15}$

13 Una exposición más pormenorizada de los cargos puede leerse en la "Información sumaria sobre el proceder José García de León y Pizarro en el tiempo de su presidencia”. Se trata de un largo expediente realizado a lo largo de 1789. AGI, Quito, 267.

14 AGI, Quito, 271. Representación de Joaquín Pareja al Consejo, Guayaquil, 4 de diciembre de 1787.

15 No fueron buenas, en efecto, las relaciones del gobernador con el cabildo de la ciudad de Guayaquil. Los enfrentamientos y desavenencias fueron continuos y transcendieron hasta la Corte. Véase Castillo, Abel Romeo: Los gobernadores de..., págs. 201 y ss. 
Tras su estudio y debate en el Consejo, la Corona cursó orden al virrey de la Nueva Granada para que indagase sobre la veracidad de los hechos denunciados, lo que fue comunicado mediante reales disposiciones de 6 de junio y 8 de julio de 1788. El entonces virrey Francisco Gil de Taboada y Lemos cumplió el encargo con celeridad y designó a Fernando Cuadrado y Valdenebro, oidor de la Audiencia quiteña, para acometer la empresa. ${ }^{16}$ Éste se había señalado como un claro opositor de los García de León y Pizarro y nunca perdonó al presidente que le relegara como juez decano del tribunal ni que se interpusiera en su carrera profesional para promocionar a su yerno Villalengua.

La decisión de Gil y Lemos de nombrarle para una investigación de tal naturaleza y que implicaba a personas tan relevantes no pareció la más adecuada y únicamente puede ser entendida desde el desconocimiento que el propio virrey tenía de la situación quiteña. ${ }^{17}$ Teniendo en cuenta estos condicionantes, no era previsible que Cuadrado actuase con la debida imparcialidad. Cuando la Corona intervino para reconducir la crisis desatada ya era demasiado tarde y para entonces los escribanos habían dejado extensa constancia de cohechos, malversaciones y conductas inmorales de la familia García de León y Pizarro. Unas veces fundadas y ciertas; otras, simples especulaciones con ánimo de medrar.

El oidor Cuadrado fue consciente, desde el mismo momento que recibió la notificación del virrey, de la oportunidad que se le ofrecía para dar satisfacción a sus intereses; sin embargo, no se le escapaban las dificultades que habría de superar para cumplir la misión que se le había encomendado y daba por sentado que el presidente Villalengua haría cuanto estuviese en su mano para frustrarla. En efecto, a mediados de marzo ya se lamentaba de que era imposible mantener en sigilo sus actuaciones a pesar de las precauciones tomadas y así se lo hacía saber al virrey. ${ }^{18} \mathrm{El} 21$ de marzo, con la citación de los primeros testigos, Cuadrado puso en marcha la pesquisa para la que contó con la ayuda del también fiscal José Merchante. Como era previ-

16 El nombramiento está fechado en Cartagena de Indias el 26 de enero de 1789 con la orden de que proceda "a recibir información sumaria puramente informativa la más sigilosa que sea dable". AGI, Quito, 272.

17 En descargo de Gil y Lemos puede argüirse que su gobierno al frente de la Nueva Granada no se prolongó más de un año, entre 1788 y 1789, y que por lo tanto no alcanzó a tomar conciencia de la realidad de aquel territorio.

18 AGI, Quito, 267. Cartas de Fernando Cuadrado a Gil y Lemos, Quito, 18 y 19 de marzo de 1789. En estas fechas ya era conocida por el público y por los propios implicados la misión de Cuadrado. 
sible, la familia Pizarro movió todos los resortes a su alcance, que no eran pocos, con el fin de obstaculizar su desarrollo. De ello se hacía eco Cuadrado cuando manifestaba a Gil y Lemos con total claridad sus temores acerca de la fuerte resistencia que había encontrado y de las barreras que debía superar. Al respecto ya anticipaba lo que unos y otros plantearían:

\begin{abstract}
"pues el último [Villalengua] en Quito donde es presidente se ha hecho temer y respetar hasta un extremo que toca en despotismo, siguiendo la máxima de su antecesor y suegro...; que Pizarro en Madrid, astuto y sagaz en disfrazar sus maldades y aparentarse inocente, no omitirá medio de sincerarse aunque sea a costa de indisponer al comisionado..., maquinará cuanto pueda para su destrucción y desconcepto". ${ }^{19}$
\end{abstract}

Estas sospechas no tardaron en hacerse realidad ya que fue proverbial la diligencia con que reaccionó el presidente de la Audiencia ante las pretensiones de Cuadrado. En efecto, Villalengua procuró frenar desde el primer momento la pesquisa sin reparar en medios ni amenazas, tal como se quejaba el fiscal al asegurar "que por medio de sus emisarios ha hecho correr la voz de terror contra los declarantes, recordándoles la residencia del presidente Araujo, en que se pusieron varias penas al juez y declarantes". ${ }^{20} \mathrm{La}$ actuación de Villalengua no quedó sólo ahí, sino que en una extensa carta también dirigida al virrey le hacía saber el cúmulo de irregularidades que concurrían en aquel proceso y el error en el que había incurrido al nombrar a Fernando Cuadrado. El panorama que dibujaba en su misiva en nada coincidía con el que pretendían ofrecer los denunciantes. Tras presentarse como un fiel vasallo, cuyo "ascenso a la presidencia fue como un sacrificio de su sumisión a la real voluntad por no incurrir en el desagrado del Soberano", arremetía con dureza contra el bando contrario. ${ }^{21}$ El centro de su crítica era precisamente Cuadrado, del que trazaba un negro retrato para concienciar a Gil y Lemos de que en absoluto era la persona apropiada para realizar la pesquisa. Éstos eran sus términos:

"Inclinado a novedades y especies exóticas, siendo tenaz y caprichoso en lo que comprende, de modo que para seguir su dictamen se necesita separarse de los preceptos

19 Ibídem. Carta reservada de Fernando Cuadrado a Gil y Lemos, Quito, 21 de marzo de 1789

20 Ibídem. Carta de Fernando Cuadrado a Gil y Lemos, Quito, 3 de abril de 1789. Recuérdese que en aquella sentencia, dada el 12 de marzo de 1747, la Corona fue realmente severa con los denunciantes y con el juez pesquisidor. Concretamente, y entre otras condenas, privó de forma perpetua de sus cargos en el Cabildo a los principales acusadores del presidente Araujo y separó temporalmente del puesto de oidor a Rubio de Arévalo, quien ejerció de juez pesquisidor.

21 Ibídem. Carta de Juan José de Villalengua a Gil y Lemos, Quito, 26 de marzo de 1789. 
legales y soberanas disposiciones, teniendo prurito por llevar la contraria particularmente en asuntos de policía y decoración de la ciudad... Que le faltan las prendas de un corazón noble y exento de envidia, por tanto no puede disimular el disgusto que le causa ver al Presidente en silla superior cuando antes tenía la de fiscal de aquella Audiencia inferior a la suya; que como tiene genio pueril, todo le hace impresión...".22

Concluía Villalengua que Cuadrado era un "enemigo declarado del Sr. D. José Pizarro mi padre político, de su hermano D. Ramón y de mí” y que su meta última no sería otra que sucederle al frente de la Audiencia sin reparar en medio alguno. Su odio - explicaba - provenía de las diferencias surgidas con el visitador general quien nunca lo recibió como hombre de su confianza. Además, alertaba sobre su comportamiento con el interesado argumento de que "es protector del famoso Don Eugenio Espejo, lo que prueba su modo de pensar".

Tampoco el fiscal Merchante salía mejor parado de los ataques de Villalengua, tal como se deduce de las siguientes palabras:

"Que su poco genio se reconoce de su insustancial locuacidad; que su genio es demasiado interesado y mísero, comiendo diariamente con Cuadrado y dándose un trato indecente a su carácter, en persona y casa; que patrocina tenazmente todas las instancias contra el gobernador de Guayaquil y obispo de Cuenca; haciendo traición a su ministerio... que todo esto le hace demasiado culpable sino disculpa sus yerros con la ignorancia en el Derecho...". ${ }^{23}$

Por todas estas razones y teniendo en cuenta el carácter de ambos personajes, el presidente Villalengua solicitaba al virrey que se les separase de la pesquisa. No satisfecho con ello, dos días después volvía a insistir sobre lo mismo. Su principal preocupación era en esta ocasión salvar a toda costa la honestidad e inocencia de su suegro, de su tío político y de él mismo. "No hallo — comenzaba señalando — expresiones con qué significar a V.E. la consternación y sorpresa que me ha causado la noticia divulgada en esta ciudad de hallarse el oidor D. Fernando Cuadrado con comisiones de V.E. para sindicar, pesquisar...". ${ }^{24}$ Disculpaba Villalengua al virrey por el erróneo nombramiento de Cuadrado sobre la base del desconocimiento que tenía de sus actos y comportamiento. Para el presidente el origen de la pes-

22 Ibídem.

23 Ibídem. El obispo de Cuenca al que alude no es otro que José Carrión y Marfil, a la sazón primo hermano de Villalengua. Fue el primer titular del recién creado obispado, desempeñando la mitra entre 1787 y 1798, año en el que fue promovido a la diócesis de Trujillo.

24 Ibídem. Carta de Juan José de Villalengua a Gil y Lemos, Quito, 28 de marzo de 1789. 
quisa no respondía más que a un desenfrenado espíritu de venganza, ya que sus autores "han sido precisamente causados, reprehendidos, castigados o perseguidos en justicia por el visitador general mi antecesor, por su hermano o por mí en nuestros respectivos gobiernos". En aquel grupo señalaba directamente a Francisco Borja, "sujeto de clase distinguida, pero que olvidado de ella no se le ha conocido otra ocupación en su vida que la de murmurar, herir y desconceptuar a sus jefes inmediatos, a los de más alta jerarquía y sus convecinos". ${ }^{25}$ Del oidor Manuel Urrutia — valedor de Borja y amigo de Cuadrado - decía que actuaba movido por el resentimiento hacia el visitador general a quien atribuía el motivo de su salida de la Audiencia de Quito con destino a la de Guadalajara.

En su opinión, los verdaderos móviles de los pesquisidores estaban bien claros y los expresó en términos tan directos como reveladores: "El $\mathrm{Sr}$. Cuadrado, con su parcial y amigo el fiscal D. José Merchante creen haberles llegado el día de su completa venganza, y por conseguirla ponen en práctica cuantos inicuos medios le sugiere su odio hacia nosotros" ${ }^{26}$ La misma desconfianza le merecían los testigos llamados a declarar en la pesquisa, todos, según decía, descontentos con el gobierno; un malestar que él consideraba fruto de las necesarias reformas emprendidas por el visitador y su deseo de reactivar la economía de la región y poner orden en la administración. ${ }^{27}$

Confesaba Villalengua sentirse vilipendiado en público y temía que el alboroto suscitado entre la población pudiera desembocar en sucesos más perniciosos, que no podría remediar "por hallarse tan débil mi autoridad". Resulta notable su habilidad para mostrarse como una víctima y transmitir a Gil y Lemos la idea de que el territorio se encontraba en situación crítica buscando el efecto de provocar en el virrey una reacción que pusiese fin a la pesquisa. Además, justificaba su postura como un acto de responsabilidad en defensa de su honor y del de su familia "porque de no hacerlo sería culpable mi silencio a vista de este público". Para contribuir a la necesaria estabilidad no dudaba en brindar alternativas para que Cuadrado no siguie-

25 Francisco de Borja era alcalde ordinario de Quito. En 1782 envió al virrey Caballero y Góngora una representación plagada de quejas contra León y Pizarro por su conducta irregular. Enterado éste de la misma, no dudó en ofrecer su versión de los hechos de la que resultaba ser Borja un intrigante y especulador con los precios de la sal y otros frutos por lo que mereció el castigo y amonestación del presidente. Ibídem. Carta de José García de León y Pizarro a Caballero y Góngora, Quito 18 de octubre de 1782 .

26 Ibídem.

27 Ibídem. Se trataba, afirmaba en su misiva, de medidas que llevaban aparejado "un conjunto de cosas y sucesos que ofrece pocos amigos y sí bastantes enemigos inexorables". 
se adelante. Entre ellas, apuntaba la conveniencia de sustituir aquella intervención por una residencia, de conformidad con la ley, y proceder a la nulidad de todo cuanto hubiese actuado el oidor, "imponiendo perpetuo silencio sobre el asunto" hasta que nuevamente resolviera el rey. ${ }^{28}$

A la luz de estas informaciones, resulta obvio que la Audiencia de Quito vivía en 1789 una conflictiva situación en la que dos bandos pugnaban por imponer sus ideas. Por un lado, el grupo encabezado por el presidente Villalengua y el oidor decano, Luis Muñoz y Cubero; por otro, el del oidor Fernando Cuadrado y el fiscal Merchante. Esta última facción procuraba por todos los medios desacreditar ante el gobierno al clan García de León y Pizarro con sucesivas denuncias y quejas; aquélla, por su parte, se esforzaba en demostrar lo infundado de semejante campaña y la baja condición de sus autores. El problema vino a agravarse con motivo de la presentación de una denuncia por parte de Manuel Núñez Balboa contra Ramón García de León y Pizarro al que acusaba de introducir mercancías de contrabando en Guayaquil y de malversación de fondos. ${ }^{29}$ La razón última de la denuncia parecía guardar relación con los sucesivos conflictos que enfrentaban a ambos protagonistas. El retrato que Villalengua ofrecía de su enemigo Núñez Balboa no dejaba dudas sobre su carácter ruin, un hombre que había sido acusado criminalmente por Pizarro, descubierto por malversación cuando ejercía de alcalde de barrio e implicado en sublevaciones y extorsiones a indios durante el tiempo que fue teniente de Puerto Viejo. ${ }^{30}$

Como era previsible, la admisión de la denuncia por el tribunal dio paso a nuevos enfrentamientos que acrecentaron la ya muy deteriorada vida de la Audiencia. Sus miembros volvieron a defender posiciones encontradas siempre de acuerdo con los intereses del bando al que se adscribían, lo cual implicaba dejar en un segundo plano la correcta administración de justicia. Por un lado, Cuadrado se apresuró a poner la causa en marcha e iniciar el turno de testigos que confirmasen los términos de la delación. Por

28 Apoyaba su demanda dibujando una situación extrema capaz de hacer reaccionar al virrey a quien rogaba que tomase en consideración el "delicado estado en que me ha reducido el inesperado golpe, el espíritu de venganza que anima el procedimiento del Juez comisionado, la despreciable calidad de los sujetos que con sus libelos han motivado la providencia, y lo que es más, las funestas consecuencias que de continuarse dicha comisión se han de seguir".

29 El contenido de la misma puede seguirse en la "Causa de capitulación puesta por Núñez de Balboa contra el gobernador de Guayaquil, Ramón García de León y Pizarro, y su teniente gobernador, José Mexía”. Quito, 1789. AGI, Quito, 271.

30 AGI, Quito, 267. Carta de Juan José de Villalengua a Gil y Lemos, Quito, 3 de abril de 1789. El desarrollo del expediente se contiene en los "Autos seguidos por la Real Justicia contra Manuel Núñez de Balboa”. AGI, Quito, 271. 
otro, el oidor Cubero, con anuencia del presidente, se ocupó de frenarla y, en cualquier caso, de poner al corriente al virrey de las intenciones maliciosas de sus oponentes.

Núñez Balboa acusó al gobernador de Guayaquil, Ramón Pizarro, de comerciar fraudulentamente con mercancías prohibidas y dinero sin registrar procedentes del puerto de Acapulco en el contexto de los negocios de cacao en los que participaba. Los efectos denunciados y que se transportaban en la nao "La Guayaquileña" podían ascender, según el delator, hasta el millón de pesos lo que representaba un grave perjuicio para la Real Hacienda. Con objeto de impedir que esta operación quedara impune, Cuadrado, con anuencia del fiscal Merchante, proveyó que el barco fuese inspeccionado a la mayor brevedad posible y siempre antes de que pudieran intervenir los oficiales reales a quienes suponía fieles al gobernador. Tal misión le fue encomendada a José Vallejo, intendente de Cuenca, a cuyo distrito pertenecía Guayaquil; éste debía intervenir con toda celeridad con el fin de que no se produjera ninguna pérdida de la carga y se evitara el fraude. Para ello se le invistió de tan amplios poderes que incluso podía, si era necesario, confinar al gobernador y a su teniente. ${ }^{31}$ Ante tal providencia, Villalengua reclamó para sí el desarrollo de los autos, argumentando que los asuntos de descamino y comiso eran privativos del gobernador y oficiales reales del puerto y si éstos estaban impedidos, era competencia suya proveer cuanto fuera necesario; además, sostenía que la Audiencia era incompetente para conocer en aquel asunto. ${ }^{32}$ Pensaba que la denuncia de Núñez Balboa no se había hecho en forma y, en todo caso, sólo sería admisible una vez hubiese sido realizada la visita del barco y no antes. ${ }^{33}$ Final-

31 AGI, Quito, 271. Representación de Fernando Cuadrado a Gil y Lemos, Quito, 18 de junio de 1789. Resulta cuanto menos sorprendente la justificación de Cuadrado para esta designación: "no hallándose alguno a propósito y libre de toda conexión ni en Guayaquil ni aún en esta ciudad a quien pudiera encargarse con satisfacción tan interesante confianza”. Bajo semejante apariencia de imparcialidad ocultaba que Vallejo estaba enfrentado a los García de León y Pizarro y era enemigo declarado del obispo de Cuenca, quien, como se ha señalado, estaba emparentado familiarmente con Villalengua.

32 Le asistía la razón a tenor de lo que establecían las leyes IV y V, Título XVII, Libro VIII de la Recopilación de Leyes de Indias. La primera, sobre "que los gobernadores, corregidores y alcaldes mayores conozcan y determinen juntos con los oficiales reales las causas de comisos"; la segunda, sobre "que las Audiencias no advoquen causas de los descaminos antes de sentenciar los jueces de primera instancia".

33 Así lo contemplaba la ley IX, del mismo título y libro: "Mandamos a los dichos nuestros oficiales que visiten los bajeles, y reconozcan los negros y mercaderías que llegare a su distrito, y aprehendan por descaminadas las que se hubieren llevado fuera de registro, procediendo de oficio, sin admitir denunciaciones de terceras personas hasta después de hecha la visita, y entonces permitimos que la admitan...". 
mente, y esto era lo más importante, sostenía que no había impedimento alguno para que él condujese la pesquisa a pesar de que el principal inculpado fuera hermano de su suegro y tío carnal de su esposa. El motivo de esta afirmación y que justificaba su intervención directa en la causa no era otro que su condición de superintendente subdelegado de Real Hacienda y que los hechos denunciados correspondían a su jurisdicción. ${ }^{34}$

El presidente Villalengua consideró que la actuación del oidor Cuadrado y de quienes le apoyaban era totalmente contraria a las ordenanzas y, sobre todo, la creyó un intento de vulnerar su autoridad y de ridiculizarle ante la población. Usando su poder logró reconducir la situación y pudo anular la providencia de la Audiencia y dictaminar que la visita del barco denunciado fuese realizada por Agustín Martín de Blas, Director General de Rentas Reales, en lugar del intendente de Cuenca. ${ }^{35}$ Convencido de que había acertado con estas medidas, esperaba del virrey un gesto de aprobación "con la conveniente demostración que tenga a bien hacer con estos ministros para reducirlos a subordinación". ${ }^{36}$ Villalengua consiguió mediante una rápida y eficaz movilización poner freno a la denuncia urdida por los enemigos de Ramón García León y Pizarro y que a todas luces consideraba falsa; al mismo tiempo creyó haber impuesto su autoridad sobre los oidores díscolos y haber repuesto la legalidad en el alto Tribunal.

La opinión de sus rivales, sin embargo, era muy distinta. Según ellos, el interés mostrado por la Audiencia para hacerse cargo de la denuncia con tanta celeridad obedecía a impedir que se consumara el delito; estaban persuadidos de que éste se habría cometido por la connivencia existente entre los oficiales reales y el propio gobernador de Guayaquil. El oidor Cuadrado estaba totalmente convencido de que la Audiencia tenía pleno derecho para entender en aquella causa; argumentaba que era legítimo obviar la legislación a la que antes se ha aludido teniendo en cuenta unas circunstancias tan especiales como aquéllas y cuando el principal objetivo de la intervención

34 AGI, Quito, 271. Representación de Juan José de Villalengua a Gil y Lemos, Quito, 18 de junio de 1789. Junto a los alegatos jurídicos que salpican este documento, sobresalen las descalificaciones contra el bando opositor con la intención de presentar el caso ante el virrey como un ejemplo más de la conspiración tramada contra su familia.

35 Tampoco era inocente este nombramiento, puesto que Martín de Blas se hallaba estrechamente vinculado al clan García de León y Pizarro. Llegó con el Visitador General ocupando la plaza de secretario y a él debió más tarde su designación como Director de Rentas. Con Villalengua seguía manteniendo la misma fidelidad que con su antecesor.

36 AGI, Quito, 271. Representación de Juan José de Villalengua a Gil y Lemos, Quito, 18 de junio de 1789. 
se encaminaba a la salvaguardia de los intereses de la Hacienda Real. $\mathrm{Su}$ punto de vista era el siguiente:

\begin{abstract}
"lo extraordinario del caso pedía alguna declinación de las reglas comunes; siendo así que los sucesos extraordinarios requieren extraordinarias medidas y providencias; ni las leyes habían previsto y resuelto la extraordinaria casualidad de comprenderse el gobernador del Puerto en el comiso y ser éste tío del Presidente Superintendente, hermano de un consejero y superior de las justicias ordinarias y oficiales reales". ${ }^{37}$
\end{abstract}

Concluía que Villalengua, por sus vínculos familiares con el denunciado, debía inhibirse de la causa "para que no se pensase que obraba con designio y a fin de solapar el comiso de su tío". Remataba su discurso señalando que el interés mostrado por el presidente de la Audiencia en el caso constituía el mejor síntoma de que se movía impulsado más por razones personales que legales.

En una tensa reunión celebrada en la Audiencia el 12 de junio los dos bandos expusieron sus tesis. A los fundamentos jurídicos esgrimidos por el presidente replicó Cuadrado con la cita de otras leyes que parecían acomodarse a sus pretensiones. En primer lugar, negó que su actuación contraviniera la mencionada ley V, Título XVII del Libro VIII, señalando que la Audiencia no advocaba ninguna causa iniciada con anterioridad por los oficiales reales, sino que daba curso a una denuncia presentada ante ella. En segundo lugar, invocó la ley VI del mismo título y libro que señalaba a las Audiencias como organismos competentes en estos casos. ${ }^{38}$ Del mismo modo, adujo la ley XI donde se consideraba a los oidores, alcaldes del crimen y otros ministros como jueces de contrabando, extravíos y comisos y se les señalaba una recompensa para que resolviesen con apremio y diligencia.

Pese a su esfuerzo, Cuadrado no logró convencer a los miembros de aquella reunión y se avino a que el alto Tribunal se inhibiera y que los autos fueran remitidos al Gobierno Superior. Con todo, dejó constancia de que la Audiencia aceptaba aquella decisión "no porque se estime incompetente

37 Ibídem. Representación de Fernando Cuadrado a Gil y Lemos, Quito, 18 de junio de 1789. Nótese que es la misma fecha que la representación de Villalengua. El virrey pudo recibir al mismo tiempo las versiones de las dos partes.

$38 \mathrm{Su}$ texto señalaba lo siguiente: "Mandamos que en los casos de descaminos de lo que se pasare a las Indias sin registro y de otras cualquier denunciaciones y comisos, se haga justicia con brevedad y precisión... y que nuestras Audiencias, Gobernadores y oficiales reales substancien y fenezcan con diligencia las causas, oídas las partes, y no permitan que con ningún pretexto se dilaten en perjuicio de nuestra Real Hacienda". 
para el juicio de tan grave negocio, ni que repute al Presidente juez privativo de él... sino tan solamente en cumplimiento de la ley XXXVI del citado Título XV". ${ }^{39}$ Fue así cómo Cuadrado aceptó que Villalengua nombrase un nuevo visitador y se apresuró a poner en conocimiento del Superior Gobierno todo lo sucedido. Cuando lo hizo no perdió la ocasión de manifestarle la gravedad del comportamiento interesado de aquél y la tesitura en que había colocado a la Audiencia.

\begin{abstract}
"Esta — escribía - ha cumplido cuanto debía al servicio del Rey en tan importante negocio. El Presidente le ha puesto impedimentos insuperables al ejercicio de su celo. Tiene mucho de singular su empeño en advocarse el proceso principiado contra pariente suyo dentro de los grados prohibidos...; el comiso denunciado trastornaría por entero la fortuna del Gobernador su tío y perjudicaría al concepto del mismo Presidente y de su suegro". ${ }^{40}$
\end{abstract}

En consecuencia, lamentaba que la Audiencia hubiera sido ultrajada y sus competencias invadidas, sentenciando que "este ejemplar funesto a la libertad y autoridad del Tribunal repone al Gobernador de Guayaquil en su antigua tranquilidad y seguridad en todas sus empresas". ${ }^{41}$

Gil y Lemos pidió la causa el 16 de octubre de 1789 pero poco pudo hacer ya en la resolución del problema, toda vez que por entonces fue nombrado nuevo virrey del Perú. Sin embargo, en el Consejo de Indias, a donde llegaban las representaciones de unos y otros, se siguió debatiendo el asunto. Fue de este modo cómo la Corte pudo tomar conciencia del alcance y gravedad de lo que acontecía en Quito. Nada hacía suponer que cuando se ordenó a Gil y Lemos que comprobase la veracidad de las quejas presentadas por algunos vecinos de Guayaquil contra su gobernador, se hubiese abierto el camino a un conflicto de grandes proporciones. La designación del oidor Cuadrado para dicha comisión facilitó sobremanera que emergieran a la luz pública las rivalidades y odios que venían fraguándose

39 Alude a la ley XXXVI, Título XV, Libro II de la Recopilación, sobre los excesos de virreyes o presidentes y la actuación de la Audiencia. En concreto, señala: "Mandamos que sucediendo casos en que a los oidores pareciere que el Virrey o Presidente excede y no guarda lo ordenado y se embarca y entromete en aquello que no debía, los Oidores hagan con el Virrey o Presidente las diligencias, prevenciones que según calidad del caso o negocio pareciere necesario... y si hechas las diligencias e instancias sobre que no pase adelante el Virrey o Presidente perseverare en lo hacer y mandar ejecutar... se cumpla y guarde lo que el Virrey o Presidente hubiere proveído, sin hacerle impedimento, ni otra demostración, y los Oidores nos den aviso particular de lo que hubiere pasado, para que Nos lo mandemos remediar como convenga"

40 AGI, Quito, 271. Representación de Fernando Cuadrado a Gil y Lemos, Quito, 18 de junio de 1789.

41 Ibídem. 
desde tiempo atrás. Como se ha dicho, la elección del virrey no fue la más acertada; además, el oidor rebasó con creces lo que se le había encomendado, ya que se extralimitó en sus funciones al tratar de incluir en la misma causa a toda la familia García de León y Pizarro. Nada de extraño tiene, por tanto, que una de las primeras medidas adoptadas por el Consejo fuera la separación total de Cuadrado en lo tocante a este caso. Sin embargo, no fue el único que se vio afectado por tan sonados incidentes. Ramón Pizarro fue removido de su plaza de Guayaquil y trasladado a la provincia de Salta en Tucumán en calidad de nuevo gobernador ${ }^{42}$ al tiempo que se ordenaba el inicio de la residencia correspondiente al cargo que acababa de dejar. Por su parte, Juan José de Villalengua fue sustituido al frente de la Audiencia con la intención de destinarlo a otro tribunal, que a la postre sería el de Guatemala. ${ }^{43}$ Con estas medidas el Consejo creyó poner fin al conflicto y abrigaba la esperanza de que cesaran las continuas recusaciones o, lo que era lo mismo, "la fermentación en dicha Audiencia con perjuicio del Real servicio y escándalo del público". ${ }^{44}$ Por la misma razón se ordenó al nuevo virrey José de Ezpeleta que archivara toda la documentación recogida por el oidor Cuadrado y que éste cesase en todas las actividades relacionadas con la pesquisa ${ }^{45}$ lo que cumplió de inmediato. ${ }^{46}$

En Quito, no obstante, los ánimos estaban lejos de calmarse y las disputas judiciales proseguían. Tanto el oidor decano Muñoz Cubero como Cuadrado, el oidor comisionado por el virrey, y el fiscal Merchante habían sido objeto de recusación por las partes contrarias. Los argumentos esgrimidos por ambas eran similares y basaban su denuncia en la parcialidad manifiesta a favor de parte. Nada de extraordinario había en ello conociendo la pertenencia del primero al clan de los Pizarro y, por otro lado, la connivencia de los últimos con Núñez Balboa. La recusación contra Cuadrado evidenciaba que las verdaderas motivaciones de la misma iban más allá de su implicación en la denuncia de Núñez Balboa. Ésta no pasaba de ser más que otro episodio en el contexto de una rivalidad que se remontaba años atrás. Como reconocía el Consejo más tarde, el origen del problema tenía "enlace íntimo con la pesquisa contra D. José García de León y Pizarro en

42 Ibídem. Real Decreto, Madrid, 7 de marzo de 1789. No hizo entrega del mando hasta pasado un año, cuando llegó su sucesor el capitán de fragata José de Aguirre e Irrisarri.

43 Abandonó Quito en abril de 1790, entregando el mando a su sucesor Antonio Mon y Velarde.

44 AGI, Quito, 271. Real Resolución, Madrid, 27 de septiembre de 1789.

45 Ibídem. Real Orden, Madrid, 24 de noviembre de 1789.

46 Ibídem. Carta de José de Ezpeleta a Antonio Porlier, Santa Fe, 19 de marzo de 1790. 
la que ha entendido el mismo oidor de orden de S.M." ${ }^{47}$ También lo entendía así el propio Cuadrado cuando relacionaba todo lo que estaba sucediendo con la persecución de que era objeto desde los tiempos de la visita general; el mismo sentido que atribuía a los sobornos, chantajes, regalos y todo tipo de estrategias puestas en práctica contra su persona por los familiares y deudos del Visitador. ${ }^{48}$

La Corona designó a Juan Moreno Avendaño para que tomara la residencia de Ramón Pizarro como gobernador de Guayaquil mediante Real Orden de 29 de enero de 1790. Había sido nombrado oidor de la Audiencia de Quito en 1788, aunque no tomó posesión del cargo hasta julio de 1789.49 Llegó, por tanto, a aquellas tierras en un tiempo en el que las tensiones en el seno del alto Tribunal alcanzaban uno de sus momentos más álgidos. Lo delicado de aquella situación motivó que tal designación se hiciera con el mayor sigilo. Se aconsejó al monarca que ni siquiera debía darse noticia del nombramiento en el Consejo ${ }^{50}$ y que sólo de forma muy reservada se comunicara la misión al virrey y al propio comisionado, con la prevención de que "el Rey había tenido por conveniente, por justos y graves motivos, el que se ejecutara en esta forma, esto es, dirigiéndose por esta vía reservada la Real Orden para tomar dicha residencia”. Aún más, para evitar mayores contratiempos y otros problemas el monarca tomaba la precaución de que Avendaño no comenzara sus pesquisas hasta que Villalengua se encontrara ya fuera del territorio. En cualquier caso, el nuevo presidente de Quito, Antonio Mon y Velarde, sí debía estar al corriente de todas estas novedades y se le exhortaba a que colaborase con Avendaño para el buen término de la residencia. ${ }^{51}$

Desgraciadamente todas aquellas prevenciones sirvieron de poco. Desde su llegada a Guayaquil, Avendaño fue captado por el clan de los Pizarro y, ya en Quito, el mismo bando trabajó para tenerlo de su parte.

47 Ibídem. Consulta del Consejo de Indias, Madrid, 18 de octubre de 1790.

48 Ibídem. Representación de Fernando Cuadrado al Consejo de Indias, Quito, 3 de febrero de 1790. Cuadrado denunció la formación de expedientes secretos contra él y la falsificación de otros con el fin de aparecer totalmente culpable ante el Consejo de todo cuanto sucedía. Asimismo, denunció que el gobernador de Guayaquil estaba presionando a los testigos que habían sido llamados a declarar en aquella causa ofreciendo cien pesos a quien facilitara noticias sobre su paradero.

49 Desde 1782 ejercía como oidor de la Audiencia de Santa Fe. Véase Burkholder, Mark A., y Chandler, D.S.: Biographical Dictionary..., pág. 222.

50 Lo excepcional de esta medida sólo parece cobrar sentido si se tiene en cuenta que el hermano del residenciado era miembro de dicho Consejo y cabría esperar alguna reacción suya para ganar tiempo.

51 AGI, Quito, 271. Real Orden, San Lorenzo, 26 de enero de 1790. 
Interesadamente Cuadrado filtró la vieja amistad que le unía con Muñoz Cubero y el trato privilegiado que le dispensaba el presidente y su esposa. ${ }^{52}$ Que Avendaño había dejado de ser la persona imparcial capaz de lograr la tranquilidad y la estabilidad en la Audiencia vino a confirmarlo el mismo presidente Mon y Velarde. Éste confesó al virrey sus dudas y reservas acerca de la idoneidad de aquella persona para culminar con éxito la misión que se le había encomendado, pues aunque le constaba la "integridad y justificación del comisionado y su aptitud para el desempeño", lo consideraba "no bien libre de imparcialidad por su particular adherencia al denunciado y decidida estimación de toda su familia". ${ }^{53}$ Impresión ésta que Mon decía haber formado "con la diaria asistencia al Tribunal". Triste espectáculo el de aquellas sesiones en las que los oidores de uno y otro bando se recusaban mutuamente. Cuando el Consejo tuvo noticias de la posición de Avendaño no tuvo más remedio que desconfiar de la idoneidad del nombramiento y, a la vista de los antecedentes, expresar su pesimismo porque "es mucho de temer que no sólo se frustre el buen deseo de S.M. de que se averigüe la verdad, sino que se encienda nueva guerra". ${ }^{54}$

Las sinceras reflexiones de Mon acerca de la crisis a la que había conducido el conflicto de la Audiencia ponen de relieve la gravedad del asunto y las serias dificultades que concurrían para la resolución del conflicto entre los jueces. Con pesimismo y desilusión reconocía haber fracasado en "aplacar el fuego de la discordia que ha devorado aquella capital y toda su provincia". Y ello fue así "por las mortales llagas que ha causado un punible espíritu de parcialidad de que nadie ha quedado exento...; se han dividido en bandos los ministros hasta llegar al escandaloso procedimiento de recusarse unos a otros, usando de medios indignos del decoro y circunspección de unos ministros del Rey" ${ }^{55}$ Estaba convencido de que su antecesor Villalengua era responsable de buena parte del problema, ya que "el que había de contener el fuego lo atizaba, siendo hijo político de uno y sobrino de otro de los acusados". Mon y Velarde estuvo al frente de la Audiencia sólo once meses y en ese breve tiempo apenas pudo contribuir a la resolución del conflicto. ${ }^{56}$

52 Ibídem. Representación de Fernando Cuadrado al Consejo de Indias, Quito, 3 de febrero de 1790 .

53 Ibídem. Carta de Antonio Mon y Velarde a José de Ezpeleta, Quito, 18 de julio de 1790.

54 Ibídem. Consulta del Consejo de Indias, Madrid, 18 de octubre de 1790.

55 Ibídem.

56 Tomó posesión el 29 de abril de 1790 y dejó la presidencia el 5 de marzo de 1791 para ocupar una plaza en el Consejo de Indias. Sin embrago, falleció en Cádiz cuando se dirigía a la Corte. 
Casi dos años después de que estallaran las desavenencias el panorama resultaba todavía desolador. Las primeras medidas implementadas por la Corona resultaron fallidas y el nuevo estudio de la causa volvió a demostrar que los testimonios y expedientes reunidos contenían demasiadas falsedades, lo que dificultaba llegar a una comprensión más o menos exacta de lo que realmente ocurría. Todas las denuncias contra los García de León y Pizarro estaban firmadas por individuos que por diversas razones se oponían a su gobierno. Las acusaciones de Joaquín Pareja, alférez real de Guayaquil, eran un compendio de quejas que evidenciaban el descontento de aquel Cabildo por las reiteradas intrusiones de Ramón Pizarro en la gestión municipal. Las de Núñez de Balboa culminaban un largo historial de desencuentros entre uno y otro. De dudosa legalidad puede considerarse su denuncia sobre el cargamento clandestino del barco "La Guayaquileña" que presentó ante la Audiencia de Quito y aún más sospechoso resulta que el oidor Cuadrado encontrara de inmediato en aquella misma ciudad testigos dispuestos a confirmar punto por punto la veracidad de aquella denuncia. Preocupado cada bando por conducir el pleito hacia el terreno que más convenía a sus intereses, cobra sentido que este oidor designara para la realización de la pesquisa al intendente de Cuenca, José Vallejo, cuya oposición a los García Pizarro era notoria y, como se ha dicho, mantenía una persistente hostilidad hacia el obispo de aquella provincia, Carrión y Marfil, que además era primo hermano del presidente Villalengua. De igual modo, se comprende que éste dejara sin efecto tales medidas y recondujera la situación con el nombramiento de Agustín Martín de Blas, deudo del clan García Pizarro, a quien debía su cargo de Director General de Rentas. ${ }^{57}$

El Consejo de Indias resumió tal estado de cosas en una frase a la que le sobra cualquier comentario: "Que los testimonios que se han tenido a la vista se hallan tan imperfectos a la verdad, que no se puede llegar a formar juicio exacto del mérito, ni aún del último estado de los negocios a que son relativos". ${ }^{58} \mathrm{Y}$ reflexionaba: "Tales gentes, tales enredos y tales prevaricatos andan en el asunto; arderán en discordias los ministros, insultarán los de un partido a los del otro impunemente. Qué remedió a tan urgente necesidad...".

57 Todas las diligencias llevadas a cabo por Villalengua en relación a la denuncia de Núñez Balboa merecieron la aprobación del virrey. AGI, Quito, 233. Carta de Juan José Villalengua al ministro de Hacienda y Guerra, Quito, 18 de septiembre de 1789.

58 AGI, Quito, 271. Consulta del Consejo de Indias, Madrid, 18 de octubre de 1790. 
Quizás por esta razón terminó cayendo en la cuenta de que la solución pasaba "por enviar un sujeto de todas calidades y que no tenga conexión en la Provincia de Quito, ni permanecer allí para estar expuesto a los tiros de la emulación". Había quedado demostrado que todos los funcionarios del distrito resultaban inhábiles para acometer una empresa tan delicada como compleja. No sólo porque cada uno a su manera estaba implicado en alguno de los bandos, sino fundamentalmente porque los encausados eran personas poderosas y habían logrado tejer una inmensa red de influencias. Con todo, a finales de noviembre de 1790 el Rey remitía las órdenes pertinentes al virrey de Santa Fe y al regente de la Audiencia quiteña, Estanislao Joaquín de Andino, para que por fin se pusiera en marcha la residencia de Ramón Pizarro. ${ }^{59}$ La misión fue encomendada en esta ocasión a Anacleto de Casas Alcalde, un juez procedente de Panamá y al que se le suponía ajeno a las rivalidades que venían consumiendo la región. El 11 de agosto de 1791 pudo iniciar por fin los autos de la misma. Sólo se presentaron trece testigos para declarar toda vez que sagazmente impidió el concurso de los amigos y enemigos del gobernador. A su conclusión únicamente resultaron contra Ramón García dos cargos de los que fue absuelto luego. El fallo definitivo exculpatorio no lo dio el Consejo de Indias hasta primeros de octubre de 1794. Para entonces los ánimos estaban ya más calmados en Quito. Alejados de aquel escenario los principales protagonistas del conflicto, las tensiones fueron remitiendo y la Audiencia pudo superar la crítica situación a la que había estado sometida.

59 Por entonces la Audiencia tenía una nueva organización, estando separada la regencia de la presidencia. Esta la ocupaba ahora el militar Luis Antonio de Guzmán. La composición del alto Tribunal en aquella época seguía, no obstante, conservando el juego de fuerzas que la dividió años atrás: Estanislao de Andino, regente; Lucas Muñoz y Cubero, oidor decano; Fernando Cuadrado y Juan Moreno Avendaño, ministros; fiscal, José Merchante y Contreras. El presidente, Guzmán, carecía de voto por no ser letrado. 